\title{
Presynaptic BK Channels Modulate Ethanol-Induced Enhancement of GABAergic Transmission in the Rat Central Amygdala Nucleus
}

\author{
Qiang Li, ${ }^{1,2,3}$ Roger Madison, ${ }^{2,3}$ and Scott D. Moore ${ }^{1,3}$ \\ Departments of ${ }^{1}$ Psychiatry and ${ }^{2}$ Neurosurgery, Duke University Medical Center, Durham, North Carolina 27710, and ${ }^{3}$ Durham VA Medical Center, \\ Durham, North Carolina 27705
}

\begin{abstract}
Large-conductance calcium-activated potassium BK channels are widely expressed in the brain and are involved in the regulation of neuronal functions such as neurotransmitter release. However, their possible role in mediating ethanol-induced GABA release is still unknown. We assessed the role of BK channels in modulating the action of ethanol on inhibitory synaptic transmission mediated via $\mathrm{GABA}_{\mathrm{A}}$ receptors in the rat central nucleus of the amygdala (CeA). Evoked IPSCs (eIPSCs) mediated by $\mathrm{GABA}_{\mathrm{A}}$ receptors were isolated from CeA neurons under whole-cell voltage clamp, and their response to selective BK channel antagonists, channel activators, or ethanol was analyzed. Blocking BK channels with the specific BK channel antagonist paxilline significantly increased the mean amplitude of eIPSCs, whereas the activation of BK channels with the channel opener NS1619 reversibly attenuated the mean amplitude of eIPSCs. Ethanol $(50 \mathrm{~mm})$ alone enhanced the amplitude of eIPSCs but failed to further enhance eIPSCs in the slices pretreated with paxilline. Bath application of either BK channel blockers significantly increased the frequency of miniature IPSCs (mIPSCs). Similarly, 50 mm ethanol alone also enhanced mIPSC frequency. Increases in mIPSC frequency by either selective BK channel antagonists or ethanol were not accompanied with changes in the amplitude of mIPSCs. Furthermore, following bath application of BK channel blockers for $10 \mathrm{~min}$, ethanol failed to further increase mIPSC frequency. Together, these results suggest that blocking BK channels mimics the effects of ethanol on GABA release and that presynaptic BK channels could serve as a target for ethanol effects in CeA.
\end{abstract}

Key words: anxiolytic; GABA; inhibition; potassium; presynaptic

\section{Introduction}

The central nucleus of the amygdala (CeA) is a critical brain region mediating anxiety- and stress-related behaviors, and is also involved in aspects of drug addiction, including drug reinforcement and stress-induced reinstatement of drug dependence (Koob et al., 1998; McBride, 2002). The CeA is a likely site where both genetic and physiological mechanisms may contribute to ethanol dependence. GABA receptor antagonists injected into various regions within the extended amygdala significantly decrease ethanol consumption in rodents, with the CeA being the most sensitive brain region (Hyytiä and Koob, 1995; Foster et al., 2004). Since the CeA GABAergic system is a key modulator of anxiety, its activity and dysregulation in CeA could greatly contribute to ethanol dependence. Withdrawal from ethanol induces the release of the stress-related peptide corticotropin-releasing

\footnotetext{
Received Dec. 17, 2013; revised July 31, 2014; accepted Aug. 28, 2014

Author contributions: Q.L. and S.D.M. designed research; Q.L. performed research; Q.L. and S.D.M. analyzed data; Q.L., R.M., and S.D.M. wrote the paper.

This study was supported by National Institute on Alcohol Abuse and Alcoholism (NIAAA) Integrative Neuroscience Initiative on Alcoholism Grants U01 AA020938 (S.D.M.) and R21 AA019553 (S.D.M.); a VA Merit Review (S.D.M.); and the VISN 6 Mental IIIness Research, Education and Clinical Centers.

The authors declare no competing financial interests.

Correspondence should be addressed to Scott D. Moore, Department of Psychiatry, Duke University Medical Center and Durham VAMC, 116A, 508 Fulton Street, Durham, NC 27705. E-mail: sdmoore@duke.edu.

DOI:10.1523/JNEUROSCI.5284-13.2014

Copyright $\odot 2014$ the authors $\quad 0270-6474 / 14 / 3413714-11 \$ 15.00 / 0$
}

factor in the CeA (Menzaghi et al., 1994; Läck et al., 2005), in addition to enhanced GABA release (Roberto et al., 2004).

Previous work has identified a large-conductance voltage- and calcium-regulated potassium current, the BK current, as a target for ethanol (Martin et al., 2008). In mouse brain, BK channels are widely distributed and are found on soma, dendrites, axons, and axon terminals, and there is a particularly high concentration of BK channels in CeA (Sausbier et al., 2006). In the lateral amygdala nucleus, BK channels regulate repetitive cell spiking and repolarization (Faber and Sah, 2002), and are involved in spike broadening following repetitive activity (Faber and Sah, 2003). BK channels can be blocked with paxilline, iberiotoxin, or low concentrations of tetraethylammonium (TEA; Faber and Sah, 2002). Thus, it would follow that alterations in these channels in the amygdala may affect ethanol-mediated anxiolysis and withdrawalinduced anxiogenesis. Given the fact that both BK channel blockers and ethanol enhance GABA release, ethanol might increase GABA release by blocking presynaptic $\mathrm{BK}$ channels.

Voltage-gated calcium channels regulate GABA release from presynaptic terminals (Poncer et al., 1997). The amygdala contains multiple types of calcium channels. In CeA neurons, there are at least of five subtypes of calcium channels that have been identified electrophysiologically in either acutely dissociated neurons or cell lines (Yu and Shinnick-Gallagher, 1997, 1998; Lee et al., 2002). In addition, voltage-gated calcium channels are reg- 
A

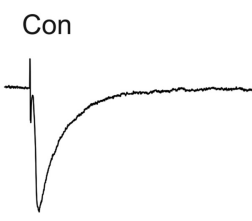

B

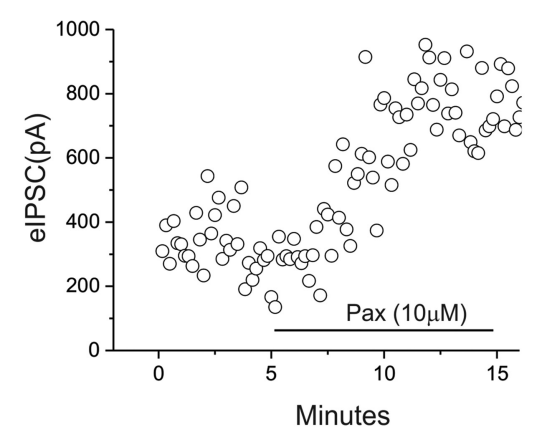

$\operatorname{Pax}(10 \mu \mathrm{M})$

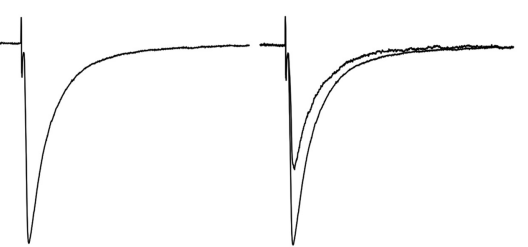

D

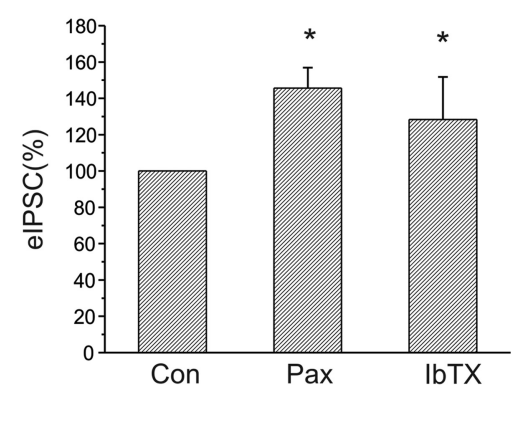

Figure 1. Blockade of $\mathrm{BK}$ channels with the antagonist paxilline $(10 \mu \mathrm{M})$ or iberiotoxin $(100 \mathrm{nM})$ significantly enhances the amplitude of eIPSCS of CeA neurons. $A$, Representative traces of elPSCs at a holding potential of $-70 \mathrm{mV}$ before and after paxilline application. $\boldsymbol{B}$, Time course of the peak amplitude of elPSCs during control and bath application of paxilline. $\boldsymbol{C}$, Superimposed traces of elPSCs under control and after bath application of iberiotoxin. $D$, Bar graph showing the mean change in peak amplitude of elPSCs after bath application of paxilline $(n=9)$ or iberiotoxin $(n=9) .{ }^{*} p<0.05$.

ulated by ethanol. Coupling of calcium ions to BK channels is a critical step for the activation of BK channels, subsequent to the regulation of synaptic release (Liu et al., 2007).

In the present study, we used whole-cell voltage patch-clamp techniques to investigate the actions of BK channel modulators on GABAergic synaptic transmission, and the interaction of BK channels, calcium channels, and ethanol on GABAergic synaptic responses in CeA neurons. Our findings indicate that inactivating BK channels with the selective BK channel blockers paxilline or iberiotoxin potentiates the amplitude of evoked IPSCs (eIPSCs), while the BK channel opener NS1619 attenuates the IPSCs. Furthermore, enhancement of GABAergic transmission in CeA induced by ethanol was dampened after BK channels were blocked with antagonists. The frequency, but not the amplitude, of spontaneous miniature IPSCs (mIPSCs) was enhanced by blocking BK channels, whereas ethanol failed to further increase the mIPSC frequency in the presence of BK channel blockers. Furthermore, ethanol inhibits calcium channels expressed in CeA neurons. Our results indicate that BK channels in the CeA may serve as a novel cellular target for ethanol, possibly mediating ethanol effects on GABAergic neurotransmission (Roberto et al., 2003), and that this action may be critical to the reinforcing and anxiolytic effects of ethanol consumption (Koob et al., 1998).

\section{Materials and Methods}

\section{Rat brain slice preparation}

All animals were treated in accordance with the guidelines outlined in the National Institutes of Health Guide for the Care and Use of Laboratory Animals, and all experimental protocols were approved by the Institutional Animal Care and Use Committees of both Duke University Medical Center and the Durham VA Medical Center. Male Sprague Dawley rats (PD18-32) were deeply anesthetized with isoflurane. The brain was quickly removed from the skull after decapitation and immediately chilled in an ice-cold, oxygenated artificial CSF (aCSF) solution containing the following (in mM): $\mathrm{NaCl} 120, \mathrm{KCl} 3.3, \mathrm{NaHCO}_{3}$ 25,
C $\operatorname{lbTX}(100 \mathrm{nM})$ (Superimposed)

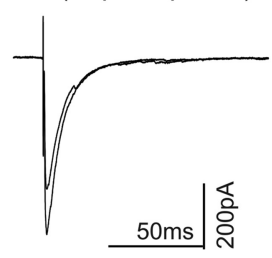

$\mathrm{NaH}_{2} \mathrm{PO}_{4} \mathrm{H}_{2} \mathrm{O} 1.23, \mathrm{CaCl}_{2} 1.8, \mathrm{MgSO}_{4}$ 1.2, and glucose 10. Coronal slices (300 $\mu \mathrm{m}$ thickness) containing the CeA were cut with a movingblade microtome, and the slices were then kept in normal oxygenated aCSF at $35^{\circ} \mathrm{C}$ for $60 \mathrm{~min}$. The slices were then kept at room temperature until used for recording.

\section{Isolation of IPSCs of the CeA neurons}

A single slice was transferred to a recording chamber that was constantly perfused $(\sim 3 \mathrm{ml} /$ min) with oxygenated aCSF at $35^{\circ} \mathrm{C}$. The CeA neurons were visualized under a Zeiss upright microscope equipped with a $40 \times$ waterimmersion objective and an enhanced differential interference contrast video microscope system. Recording electrodes with resistance of 4-8 $\mathrm{M} \Omega$ were pulled from borosilicate glass capillaries (1.5 mm outer diameter) using a P97 electrode puller. Access resistance and input capacitance were electronically compensated by $\sim 60-70 \%$ and monitored throughout the experiment to confirm the stability of the recording. The solution filling the pipette contained the following (in $\mathrm{mm}$ ): Cs-gluconate 130, CsCL 10, EGTA 0.2, Mg ATP 4, Tri-GTP 0.3 , HEPES 10, and QX-3146. The $\mathrm{pH}$ was adjusted to 7.4 with $\mathrm{CsOH}$, and osmolarity was 290 mOsm. Given the $\mathrm{Cl}^{-}$concentrations of aCSF and pipette solutions, the $\mathrm{Cl}^{-}$equilibrium potential was $\sim 0 \mathrm{mV}$, and thus produced an inward current when the neurons were voltage clamped at $-70 \mathrm{mV}$. Signals were recorded with an Axopatch 200B amplifier, filtered at $5 \mathrm{kHz}$, and digitized at 10 $\mathrm{kHz}$ through a Digidata 1440 interface controlled by pCLAMP10 software (Molecular Devices).

Evoked IPSCs. A monopolar stimulating electrode was placed $\sim 50 \mu \mathrm{m}$ away from the patched neurons. Stimuli were delivered at a frequency of $0.01 \mathrm{~Hz}$ with $1 \mathrm{~ms}$ pulse durations. In the presence of kynurenic acid (3 $\mathrm{mM})$ or AP5 $(50 \mu \mathrm{M})$, DNQX $(20 \mu \mathrm{M})$, and CGP55845 (1 $\mu \mathrm{M})$ to block glutamatergic transmission and presynaptic $\mathrm{GABA}_{\mathrm{B}}$ autoreceptors, respectively, eIPSCs were isolated from CeA neurons held at $-70 \mathrm{mV}$. After the input-output curve was first determined, the stimulus intensity was adjusted to evoke a response at $50 \%$ of the maximum IPSC amplitude.

Spontaneous spontaneous and miniature IPSCs. In the presence of kynurenic acid (3 mM) or AP5 (50 $\mu \mathrm{M})$, DNQX (20 $\mu \mathrm{M})$, and CGP55845 $(1 \mu \mathrm{M})$, we isolated GABAergic spontaneous IPSCs (sIPSCs) from CeA neurons held at $-70 \mathrm{mV}$. We also recorded mIPSCs from CeA neurons held at $-70 \mathrm{mV}$ in the additional presence of tetrodotoxin (TTX; $1 \mu \mathrm{M}$ ). In all instances, evoked and spontaneous GABAergic IPSCs were recorded for at least $5 \mathrm{~min}$ to establish stable baseline values. Without altering the perfusion rate and temperature, the perfusion medium was then switched to one containing the indicated concentrations of the drug for at least $10 \mathrm{~min}$. mIPSCs were analyzed using Clampfit 10 software. The threshold for the detection of mIPSC was used and followed by visual inspection to ensure the accuracy of detection.

Isolation of voltage-gated calcium currents. Whole-cell voltagedependent calcium currents were isolated from CeA neurons under voltage-clamp conditions. For these studies, the external solution contained the following (in mM): $\mathrm{NaCl} 120$, TEA-Cl 20, $\mathrm{CaCl}_{2} 2, \mathrm{MgCl}_{2} 1$, glucose 10, HEPES 5, and TTX 0.001. pH was adjusted to 7.3 with $\mathrm{HCl}$. In a subset of recordings, calcium was replaced with $\mathrm{BaCl}(10 \mathrm{~mm})$ to isolate currents in which barium could act as the charge carrier through calcium channels. The internal solution contained the following (in $\mathrm{mm}$ ): $\mathrm{CsCL}$ 115, TEA-CL 20, $\mathrm{CaCl}_{2} 1, \mathrm{MgCl}_{2}$ 2, EGTA 11, Mg ATP 2, Tri-GTP 0.3, and HEPES 10. Leak currents were on-line subtracted using a $\mathrm{P} / \mathrm{N}(n=4)$ protocol. The relationship of voltage and whole calcium currents or barium currents was determined by applying $500 \mathrm{~ms}$ depolarizing steps from 
-90 to $40 \mathrm{mV}$ in $10 \mathrm{mV}$ increments. To test the effects of ethanol on calcium currents, CeA neurons were held at $-90 \mathrm{mV}$, and currents were elicited by a $500 \mathrm{~ms}$ single voltage step to $0 \mathrm{mV}$ at intervals of $10 \mathrm{~s}$.

$B K$ channel blockade. The selective specific BK channels blockers, $(2 R, 4 \mathrm{~b} S, 6 \mathrm{a} S, 12 \mathrm{~b} S$, $12 \mathrm{c} R, 14 \mathrm{a} S$ )-4b-hydroxy-2-(1-hydroxy-1methylethyl)-12b,12c-dimethyl-5,6,6a,7,12, $12 \mathrm{~b}, 12 \mathrm{c}, 13,14,14 \mathrm{a}$-decahydro- $\mathrm{H}$-chromeno $\left[5^{\prime}, 6^{\prime}: 6,7\right]$ indeno $[1,2-b]$ indol-3 $(4 \mathrm{~b} H)$-one (paxilline) and the neurotoxin iberiotoxin were prepared as a stock solution. The BK channel activator/opener NS1619 was dissolved in DMSO. Each compound was used fresh on the day of the experiment and was bath applied. In the experiments in which DMSO was used for preparing stock solution, an equal concentration of DMSO was also added into aCSF throughout experiments. All drugs were purchased from Tocris Bioscience.

Although the CeA neurons are heterogeneous with distinct firing properties, we did not attempt to characterize the responses of cells to drugs based on the identity of each neuron encountered; results are pooled from a total population of $148 \mathrm{CeA}$ neurons. Data are presented as the mean \pm SEM unless otherwise indicated. All statistical analysis and graphic presentations were performed using Clampfit 10.3 and Origin 8.0 (Microcal Software). The Kolmogorov-Smirnov (K-S) test was used to compare cumulative distributions of mIPSC parameters in the absence and presence of the test drugs. $p<0.05$ was considered significant for both tests. Student's $t$ test or one-way ANOVA, when appropriate, was also used to determine the statistical significance between means.

\section{Results}

\section{BK channel blockade enhances} amplitude of eIPSCs in CeA neurons

We first sought to determine whether BK channels contribute to synaptic transmission in CeA neurons by measuring synaptic events elicited by electrical stimulation. In the presence of excitatory neurotransmitter antagonists, $\mathrm{GABA}_{\mathrm{A}}$ receptor-mediated eIPSCs were inward currents when the cell was held at $-70 \mathrm{mV}$, as shown in Figure 1, and were completely blocked by bath application of the $\mathrm{GABA}_{\mathrm{A}}$ receptor blocker bicuculline $(20 \mu \mathrm{M})$. In the following study, only one recording was performed after each slice was treated with a BK channel blocker, a channel opener, or ethanol.

Bath application of the BK channel blocker paxilline $(10 \mu \mathrm{M})$ caused a significant increase in the amplitude of eIPSCs (Fig. $1 A$ ). Figure $1 B$ shows a time course of the responsiveness of the same CeA neuron to the administration of paxilline. In addition, we tested another BK channel blocker, iberiotoxin, a specific BK channel blocker with a high affinity to BK channels that do not

\section{A}
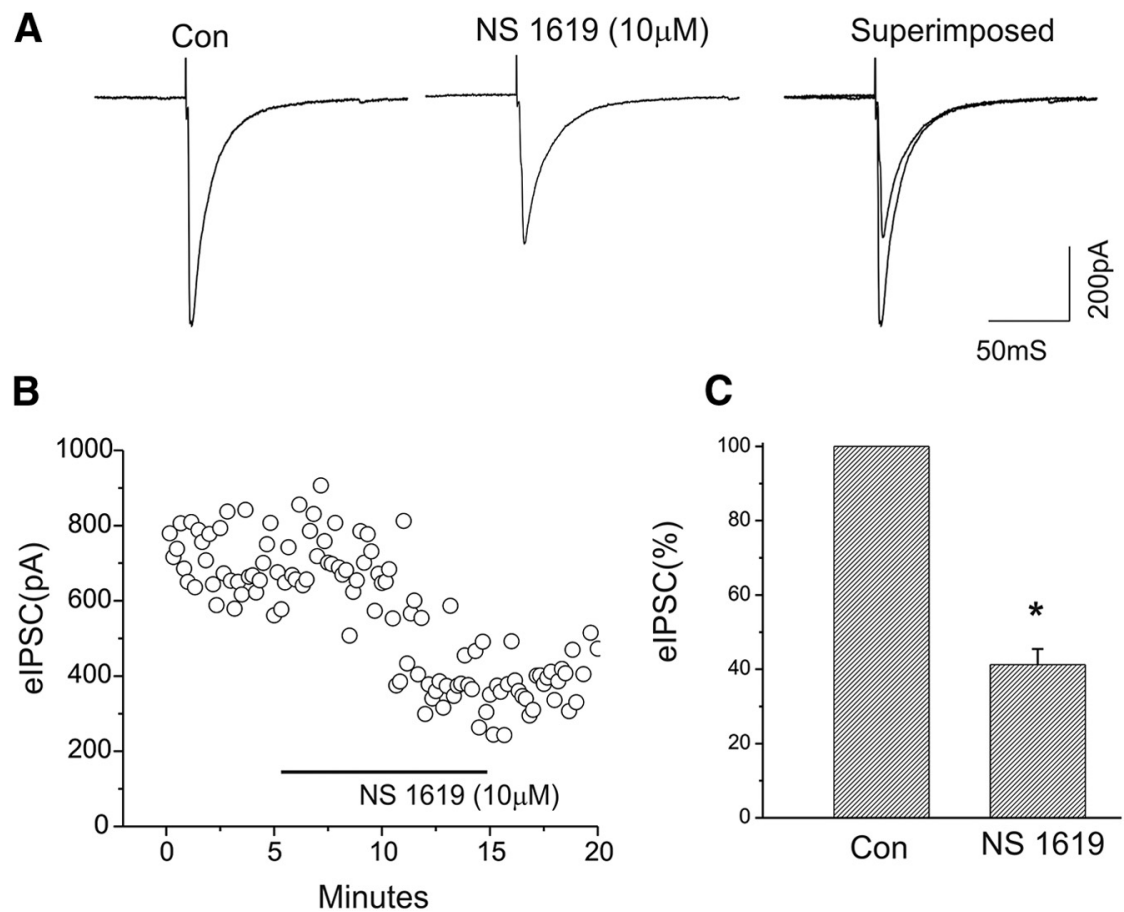

C

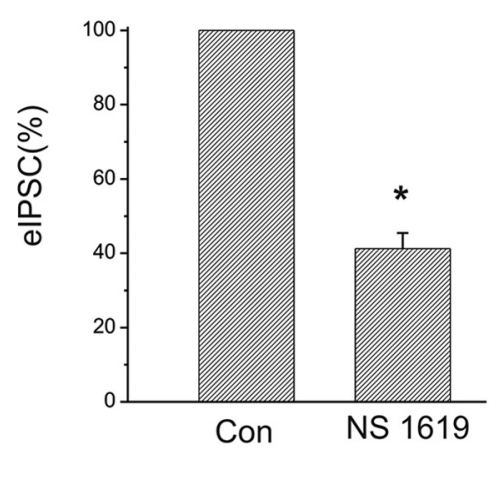

Figure 2. Enhancement of BK channel activity with the BK channel opener NS-1619 significantly reduces the amplitude of eIPSCS of CeA neurons. $A$, Representative traces of elPSCs at a holding potential of $-70 \mathrm{mV}$ before and after NS1619 application. In this neuron, bath application of NS1619 resulted in a reduction in the amplitude of elPSCs to $39.8 \%$ of control, as demonstrated in $\boldsymbol{A}$. B, Time course of the peak amplitude of elPSCS during control and bath application of NS1619. C, Bar graph showing the mean change in the peak amplitude of elPSCs after bath application of NS1619 $\left({ }^{*} p<0.05 ; n=6\right)$.
Con

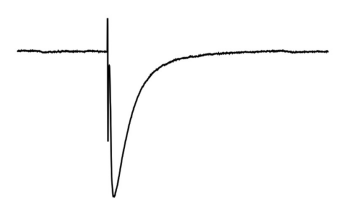

B

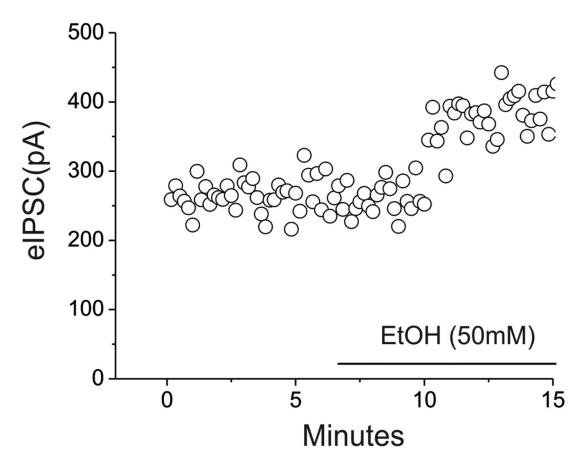

$\mathrm{EtOH}(50 \mathrm{mM})$

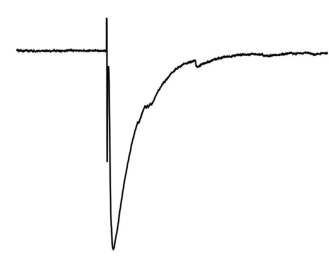

C
Superimposed
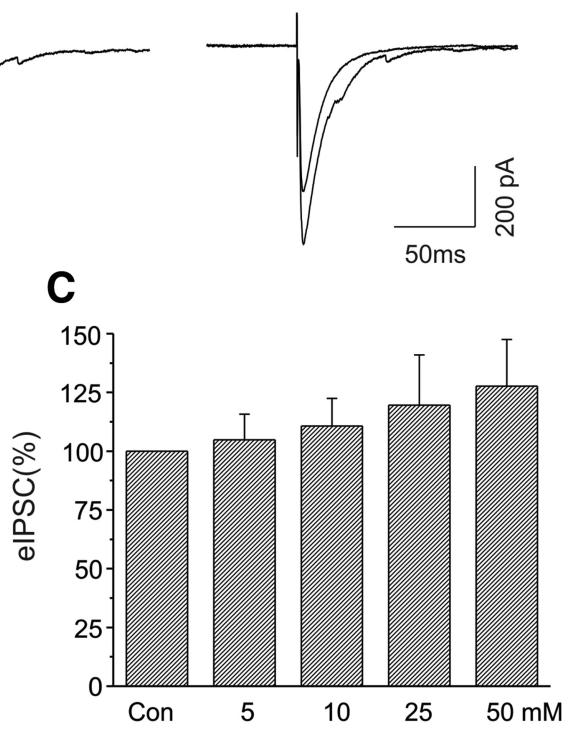

Figure 3. Enhancement of the amplitude of elPSCs of CeA neurons by ethanol $(50 \mathrm{~mm}) \cdot A$, Representative traces of elPSCs at the holding potential of $-70 \mathrm{mV}$ before and after ethanol application. In this neuron, $50 \mathrm{~mm}$ ethanol increased the amplitude of elPSCs by $30 \%$ over baseline. $\boldsymbol{B}$, Time course of the peak amplitude of elPSCs during control and bath application of ethanol. $\boldsymbol{C}$, Bar graph showing the mean change in the peak amplitude of elPSCs after bath applications of $5(n=7), 10(n=5), 25(n=5)$, and $50 \mathrm{~mm}$ $(n=7)$ ethanol $\left(F_{(3,20)}=25.1 ; p<0.001\right.$, one-way ANOVA $)$.

contain $\beta-4$ subunits, on the amplitude of eIPSCs. Similar to paxilline, iberiotoxin (100 nM) also significantly increased the amplitude of eIPSCs, as shown in Figure 1C. We examined the effects of paxilline $(n=9)$ and iberiotoxin $(n=9)$, with the mean results shown in 
A
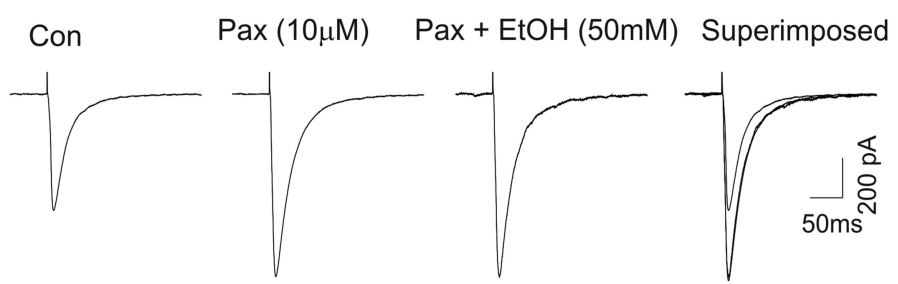

B

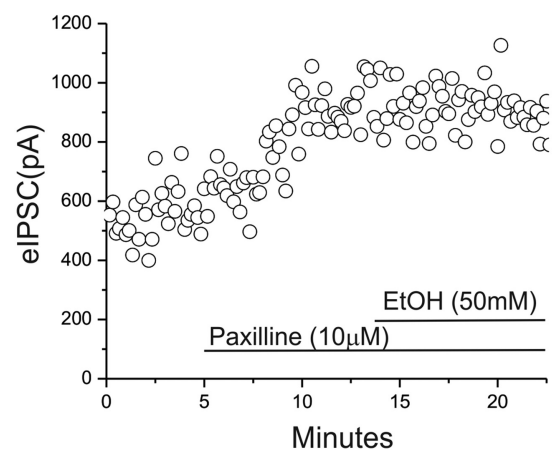

tion of the BK channel activator/opener NS1619 $(10 \mu \mathrm{M})$ induced a marked reduction in the amplitude of eIPSCs (Fig. 2). Figure $2 B$ shows a time course of the responsiveness of the same CeA neuron to bath administration of NS1619 (same neuron as in Fig. 2A). Changes in the inhibition of eIPSCs following bath application of NS1619 ranged from $24.9 \%$ to $45.3 \%$ in 6 CeA cells tested, and the mean change in the suppression of eIPSCs is summarized in Figure 2C. These results indicate that the activation of BK channels with a channel opener/activator attenuates GABAergic synaptic transmission in CeA.

\section{Ethanol increases the amplitude of} eIPSCs of CeA neurons

We further assessed the effects of ethanol on evoked IPSCs of CeA neurons in our slice preparations. Consistent with previous reports (Roberto et al., 2003, 2006; Kang-Park et al., 2007, 2009, 2013), bath application of ethanol (50 mM) enhanced the amplitude of eIPSCs of CeA neurons. Representative responses to $50 \mathrm{~mm}$ ethanol are shown in Figure $3 A$, and the time course of responses is shown in Figure $3 B$. We also found that bath application of 5 $(n=7), 10(n=5), 25(n=5)$, and $50 \mathrm{~mm}$ $(n=7)$ ethanol increased the mean amplitudes of eIPSCs in a dose-dependent manner (Fig. $3 C ; F_{(3,20)}=25.1 ; p<0.001$, one-way ANOVA).

Ethanol fails to increase the amplitude of eIPSCs in slices pretreated with BK channel antagonists

Our present results suggest that both BK channel blockers and ethanol can enhance GABAergic synaptic transmission in the CeA neurons. However, it is unknown whether BK channels might mediate the ethanol-induced enhancement of eIPSCs. We next tested the effect of BK channel blockade on subsequent actions of ethanol in GABAergic synaptic transmission in CeA. We found that, in the presence of the BK channel blocker paxilline, ethanol (50 $\mathrm{mm}$ ), which was shown to significantly increase the amplitude of eIPSCs (Fig. 3C) in the present study, failed to cause a further increase in the amplitude of eIPSCs. As shown in Figure 4A, paxilline $(10 \mu \mathrm{M})$ was first bath applied and increased the amplitude of eIPSCs, as Figure $1 D$. Both paxilline and iberiotoxin significantly increased mean eIPSC amplitude $(p<0.05$, paired $t$ test $)$.

\section{Activation of BK channels reduces the amplitude of eIPSCs in} CeA neurons

We next examined whether the activation of BK channels could alter GABAergic synaptic transmission in the CeA. Bath applica-

observed previously. Subsequently, the addition of $50 \mathrm{~mm}$ ethanol to the aCSF did not further alter the amplitude of eIPSCs. Responses to paxilline and ethanol are depicted in Figure 4, $A$ and $B$. In the five cells tested, we observed no change in the amplitude of eIPSCs after ethanol was coapplied with paxilline (Fig. 4C). These results suggest that BK channel blockade 
mimics the actions of ethanol on GABAergic synaptic function in CeA.

In another set of experiments, the presynaptic effects of ethanol on GABA release were also determined by applying paired pulse stimuli to CeA neurons. At a holding potential of $-70 \mathrm{mV}$, two pulses at a $50 \mathrm{~ms}$ interpulse interval were applied to afferents to CeA neurons, the paired pulse facilitation was recorded, and the IPSC2/IPSC1 ratio was measured. We tested the effect of ethanol ( $50 \mathrm{~mm})$ on the ratio of paired pulse facilitation in five CeA neurons, and our results indicate that the ratio of paired pulse facilitation was significantly reduced (mean \pm SEM: baseline, 1.29 \pm 0.06 ; ethanol, $1.15 \pm 0.06 ; p<$ 0.05 , paired $t$ test), indicating that there is an increase in synaptic release in the presence of ethanol (data not shown).

We continued to assess the role of BK channels in regulating GABAergic synaptic transmission by bath application of iberiotoxin, an antagonist selective for BK channels that do not contain the $\beta 4$ subunit. In a separate set of experiments, iberiotoxin (100 nM) increased the amplitude of eEPSCs by $29 \%(n=5 ; p<0.05)$. The addition of 50 $\mathrm{mM} \mathrm{EtOH}$ to the aCSF containing iberiotoxin did not significantly further enhance the amplitude of eIPSCs (Fig. 5). These results suggest that BK channel blockade mimics the actions of ethanol on GABAergic synaptic function in $\mathrm{CeA}$, and the $\beta 4$ subunit is not required for this action.

Effects of the specific BK channel blocker iberiotoxin on the frequency of sIPSCs in CeA neurons

We pharmacologically isolated sIPSCs from CeA neurons held at $-70 \mathrm{mV}$. Bath application of iberiotoxin $(100 \mathrm{nM})$ decreased the interevent intervals of sIPSCs, but subsequent coapplication of $50 \mathrm{~mm} \mathrm{EtOH}$ showed no further decrease in the sIPSC interevent interval (Fig. 6A). We tested the effects of iberiotoxin and EtOH on sIPSCs in seven CeA neurons. Pooled data are shown in Figure $6 B$, though in two of seven neurons EtOH (50 mM) still tended to slightly increase sIPSC frequency (data not shown). Neither iberiotoxin nor iberiotoxin plus EtOH significantly increased the amplitude (Fig. 6C) of sIPSCs.

\section{Ethanol increases the frequency of mIPSCs of CeA neurons} The previous results indicate that the activation or inactivation of BK channels alters the effect of ethanol on GABAergic transmission in CeA neurons. We next addressed the locus of $\mathrm{BK}$ channel involvement by measuring the spontaneous quantal release of GABA by examining mIPSCs. The alteration in mIPSC frequency is considered to be a reflection of presynaptic terminal excitability.

In the presence of the fast sodium channel blocker TTX (1.0 $\mu \mathrm{M})$, excitatory glutamatergic receptor antagonists, and a $\mathrm{GABA}_{\mathrm{B}}$ receptor antagonist, mIPSCs were isolated from CeA neurons held at $-70 \mathrm{mV}$. We first assessed the effect of ethanol on mIPSCs of CeA neurons. As shown in Figure 7A, bath appli- cation of $50 \mathrm{~mm}$ ethanol significantly increased the frequency of mIPSCs, as demonstrated by a significant shortening of the interevent intervals shown in Figure $7 B(p<0.001, \mathrm{~K}-\mathrm{S}$ test $)$. Figure $7 C$ shows a statistically significant difference in the averaged interevent intervals between control and ethanol $(n=5$, $p<0.05)$. Furthermore, ethanol did not significantly alter the average amplitude of mIPSCs, as shown in Figure $7 C(n=5 ; p>0.05)$.

BK channel blockade also increases the frequency of mIPSCs We then examined the effects of the BK channel blocker paxilline on the frequency and amplitude of mIPSCs in similar experiments. As illustrated in Figure $8 A, 10 \mu \mathrm{M}$ paxilline increased the frequency of mIPSCs in CeA neurons. A cumulative distribution of interevent intervals in this cell significantly shifted to the left compared with control ( $p<0.001, \mathrm{~K}-\mathrm{S}$ test; Fig. $8 B)$. There was a significant change in mean interevent intervals between paxilline and control (Fig. $8 C ; n=7 ; p<0.05$ ).

Ethanol fails to increase the frequency of mIPSCs in slices pretreated with BK channel antagonists

We next examined whether the ethanol-induced enhancement of mIPSC frequency could be occluded after BK channel blockade, as observed previously in eIPSC responses. As shown in Figure 8A, 
A
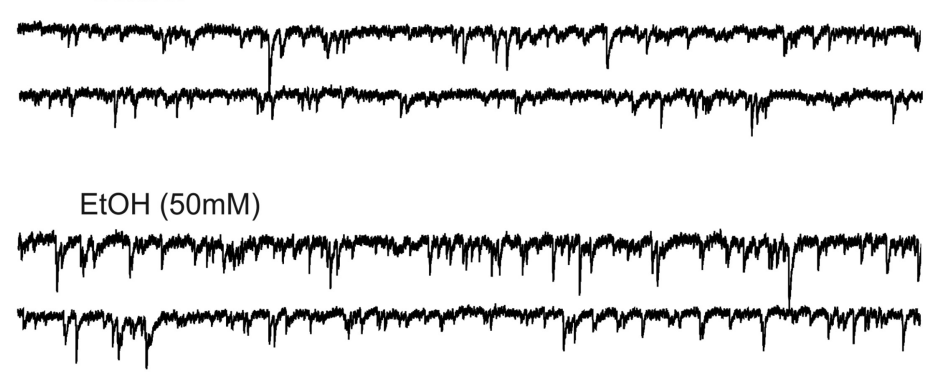

BMI $(20 \mu \mathrm{M})$

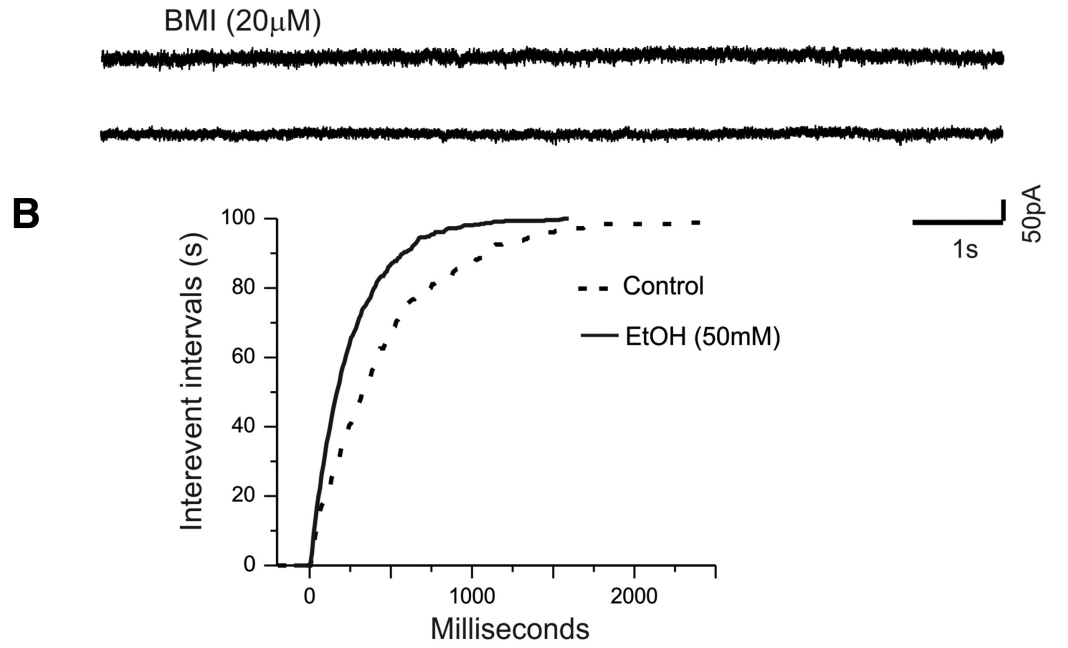

C
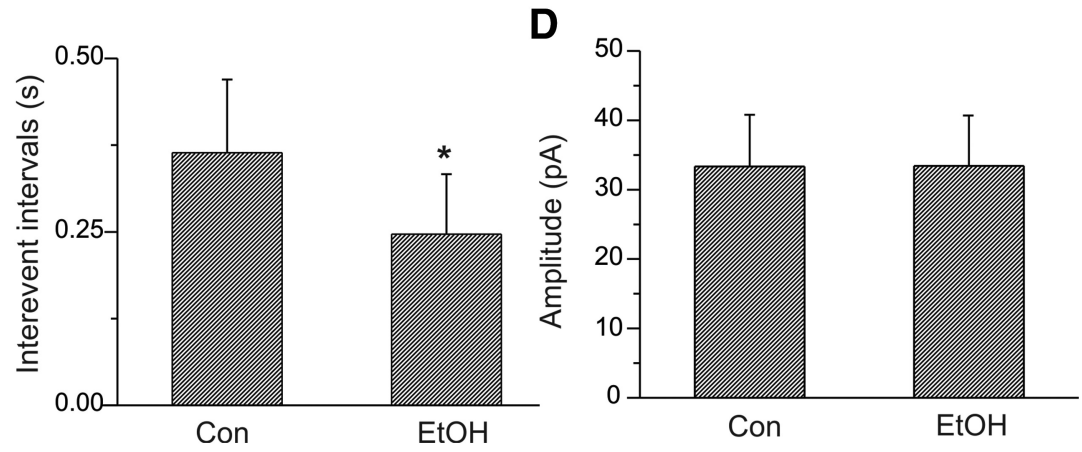

Figure 7. Effects of ethanol on mIPSCS of CeA neurons. $A$, Traces show mIPSCS recorded from a CeA neuron before and during bath application of ethanol. The GABA receptor blocker bicuculline completely blocks mIPSCS. B, C, Ethanol shifts the cumulative distribution of the interevent intervals of mIPSCs to the left $(p<0.001$, K-S test; $\boldsymbol{B})$ and reduces the mean interevent interval of mIPSCs significantly $\left(\boldsymbol{C} ;{ }^{*} p<0.05 ; n=5\right)$. $\boldsymbol{D}$, Ethanol does not significantly alter the mean amplitude of mIPSCs.

increased the frequency of mIPSCs in this neuron, but the addition of EtOH (50 $\mathrm{mm})$ did not further increase the frequency. Figure 9, $B$ and $C$, shows the effects of iberiotoxin and ethanol on the interevent intervals (Fig. 9B) and amplitude (Fig. 9C) of mISPCs. Iberiotoxin significantly decreased mean interevent intervals ( $p<0.05$, paired $t$ test) but did not change the amplitude of mIPSCs.

\section{Neither BK channel blockers nor ethanol alter the kinetics of mIPSCs of CeA neurons}

Our mIPSC data indicate that presynaptic BK channels may be responsible for the effects of both BK channel blockade and ethanol on inhibitory neurotransmitter release. We further explored this by analyzing the kinetic properties of mIPSCs of the CeA neurons recorded in the presence of a BK channel blocker or ethanol. As shown in Figure 10, there is no change in the rise time or decay time of averaged mIPSCs during control, or bath application of paxilline $(10 \mu \mathrm{M})$ or ethanol (50 mM).

\section{Ethanol inhibits whole-cell total} calcium currents in CeA neurons $\mathrm{BK}$ channels have an obligate interaction with voltage-dependent calcium channels (Berkefeld et al., 2006). In addition, calcium is required for ethanol actions on $\mathrm{BK}$ channels, while ethanol also facilitates the binding of calcium to the calcium-sensing bowl on the BK channel complex (Liu et al., 2008). Voltage-gated calcium channels are sensitive to the inhibitory effects of ethanol (Walter and Messing, 1999). We therefore performed experiments to determine whether calcium channels in CeA neurons are also affected by ethanol. Since there is as yet little information on whether ethanol modulates calcium currents in CeA neurons, we thus focused on

bath application of paxilline $(10 \mu \mathrm{M})$ caused an increase in the frequency of mIPSCs of this CeA cell. In the presence of paxilline, $50 \mathrm{~mm}$ ethanol was bath applied for $10 \mathrm{~min}$ and did not further alter the frequency of mIPSCs. Cumulative analysis of interevent intervals of the frequency of mIPSCs indicated that there was a significant change in the frequency between paxilline and control $(p<0.001, \mathrm{~K}-\mathrm{S}$ test), but no change in the cumulative distribution of interevent intervals between paxilline and paxilline plus ethanol ( $p>0.05$, K-S test; Fig. $8 B$ ). The addition of $10 \mu \mathrm{M}$ paxilline significantly reduced mean interevent intervals (Fig. $8 C$; $n=4 ; p<0.05$ ), but subsequent addition of $50 \mathrm{~mm}$ ethanol did not further increase the interevent intervals (Fig. $8 C ; n=4 ; p>$ 0.05). Additionally, neither paxilline nor ethanol altered the mean amplitude of mIPSCs (Fig. $8 D ; n=4 ; p>0.05$ ).

In a separate set of experiments, the responsiveness of mIPSCs to iberiotoxin and ethanol was tested in seven CeA neurons. As shown in Figure 9A, bath application of iberiotoxin (100 nM) the action of ethanol only on whole-cell calcium currents in the present study. Calcium currents were elicited by $500 \mathrm{~ms}$ depolarizing test steps between -90 and $60 \mathrm{mV}$ in $10 \mathrm{mV}$ increments. The current-voltage relationship of the total calcium current in the CeA neurons is shown in Figure $11 A(n=9)$. Total calcium currents were activated at a voltage of $-40 \mathrm{mV}$ and reached a peak at approximately $-10 \mathrm{mV}$. Bath application of a nonselective calcium channels blocker, cadmium $(100 \mu \mathrm{M})$, blocked the calcium currents, as demonstrated in Figure $11 B$. We isolated the total calcium current using internal recording solutions using either calcium or barium as the charge carriers (Zucca and Valenzuela, 2010). We measured the peak of the total calcium current and a sustained component of the current at $450 \mathrm{~ms}$ following a depolarizing pulse. The late and sustained components of the currents are thought to be associated with L-type calcium channels (Tsien et al., 1988). 
Figure $11 C$ shows the voltage responses of the total of calcium channels of CeA neurons before and after bath application of $25 \mathrm{~mm}(n=5)$ and $50 \mathrm{~mm}(n=$ 11) ethanol. Ethanol significantly inhibits both peak and sustained components of total calcium current (Fig. 11D). In a separate set of experiments, the internal recording solution containing barium (to reduce current rundown) as the charge carriers was used to isolate the total barium currents (Zucca and Valenzuela, 2010). Similarly, bath application of 25 $\mathrm{mm}(n=11)$ and $50 \mathrm{~mm}(n=8)$ ethanol suppressed the peak and sustained components of the total barium currents (Fig. $11 E)$. Summarized data are shown in Figure $11 F$.

\section{Discussion}

We chose to perform this study in the $\mathrm{CeA}$, as it is a likely site where genetic and physiological mechanisms may contribute to ethanol dependence. As a relatively simple chemical, ethanol likely acts on multiple molecular targets, including ion channels. A recent report demonstrates a site on the BK channel that meets criteria for a likely interaction with ethanol (Bukiya et al., 2014). The CeA also contains a high concentration of BK channels (Sausbier et al., 2006), although, to our knowledge, this is the first study to document the role of BK channels in synaptic transmission in the CeA.

The BK channel is highly conserved in multiple species from invertebrates through humans, and has recently been found to be essential for the behavioral effects of ethanol in Caenorhabditis elegans (Davis et al., 2014). In Drosophila melanogaster, the presence of functional $\mathrm{BK}$ channels is required for the acquisition of acute tolerance to ethanol sedation (Cowmeadow et al., 2006). In vertebrates, the BK channel appears particularly relevant to ethanol studies given that it interacts with multiple protein complexes critical for synaptic function, specifically neurotransmitter vesicle fusion such as SNARE complexes and dynamin-1 (Gorini et al., 2010).

In a variety of brain regions, BK channel activity regulates repetitive cell spiking and repolarization (Faber and Sah, 2002) and spike broadening following repetitive activity (Faber and Sah, 2003); this spike broadening is associated with enhanced transmitter release (Jackson et al., 1991). Our previous work in CeA also demonstrates a consistent effect of ethanol on neuropeptide transmitter release (Nie et al., 2004; Kang-Park et al., 2007, 2009, 2013). Although we speculate that occlusion inhibition of BK activity by ethanol may contribute to this enhanced release, our data thus far support this only indirectly. However,
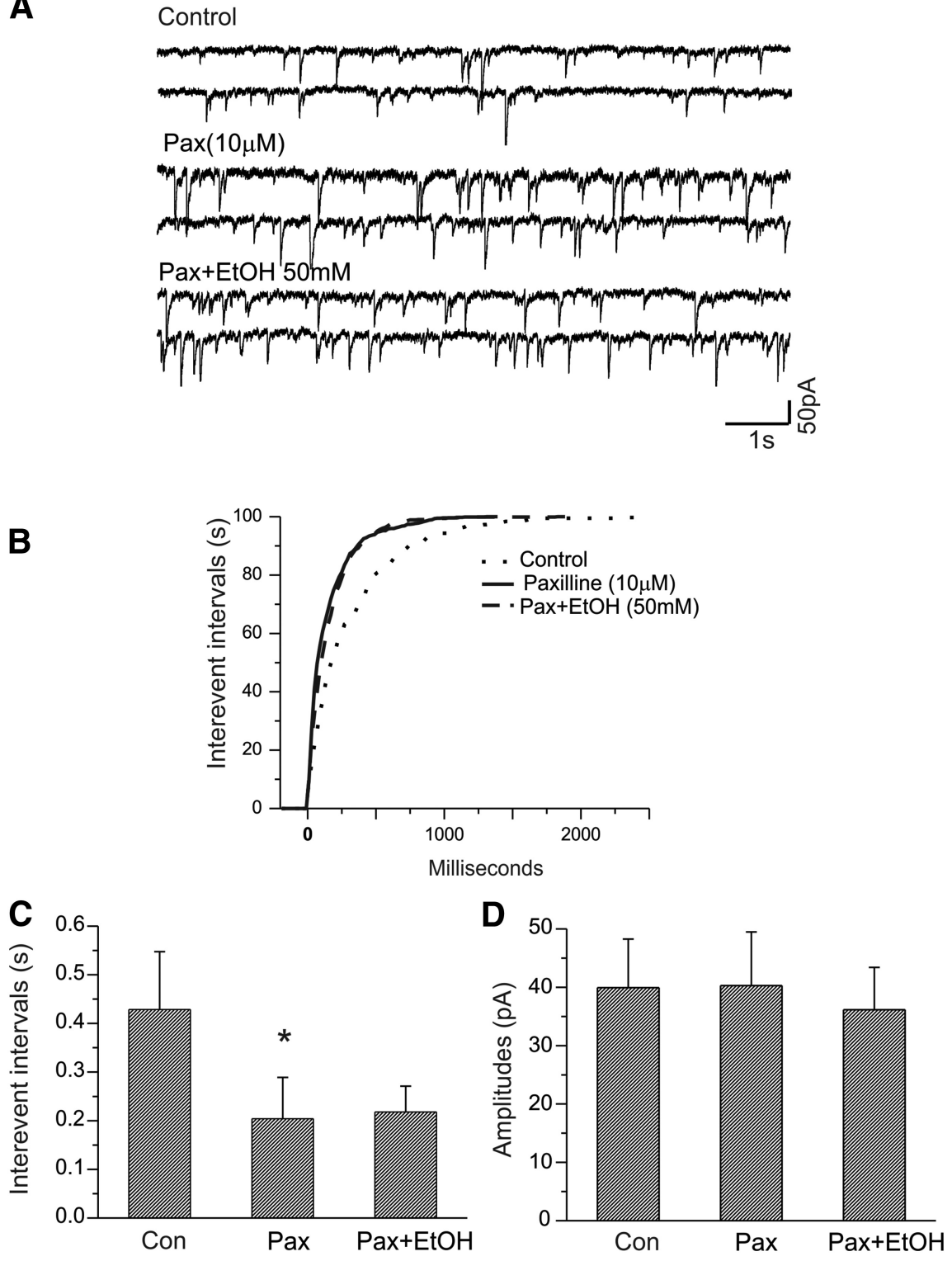

Figure 8. Ethanol fails to increase the frequency of mIPSCs of CeA neurons in the presence of the selective BK channel blocker paxilline. $\boldsymbol{A}$, Traces show mIPSCs recorded from a CeA neuron at a holding potential of $-70 \mathrm{mV}$ under control, during bath application of paxilline alone, and during coapplication of paxilline and ethanol. $\boldsymbol{B}$, Paxilline alone shifts the cumulative distribuin the cumulative distribution of mIPSC frequency after bath application of ethanol (50 mM). C, The mean interevent interval of mIPSCs was significantly decreased following bath application of paxilline $\left({ }^{*} p<0.05\right.$, paired $t$ test), but ethanol no longer alters interevent intervals of mIPSCs in the presence of paxilline. $D$, There are no changes in the mean amplitude of mIPSCs after bath application of either paxilline or paxilline plus ethanol $(p>0.05)$.

work in the isolated neurohypophysis also suggests a direct role of BK channels in the regulation of neuropeptide release from presynaptic sites (Knott et al., 2000). In addition, THE presence of BK channels on specific neuron types in the pituitary regulate burst activity, thereby modulating hormone secretion levels in different cell types (Tabak et al., 2011).

Our data contrast in several respects to previous reports of ethanol on BK channels, which have shown BK channels potentiated, inhibited, or insensitive to ethanol (Martin et al., 2008; Bukiya et al., 2009; Wynne et al., 2009). To our knowledge, our data are the first to demonstrate the inhibition of neuronal BK channels by ethanol. Importantly, in cultured cells the BK channel is highly sensitive to low concentrations (10-20 mM) of eth- 
A

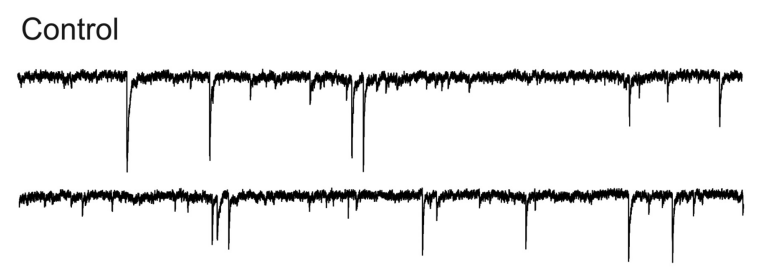

$\operatorname{lbTX}(100 \mathrm{nM})$

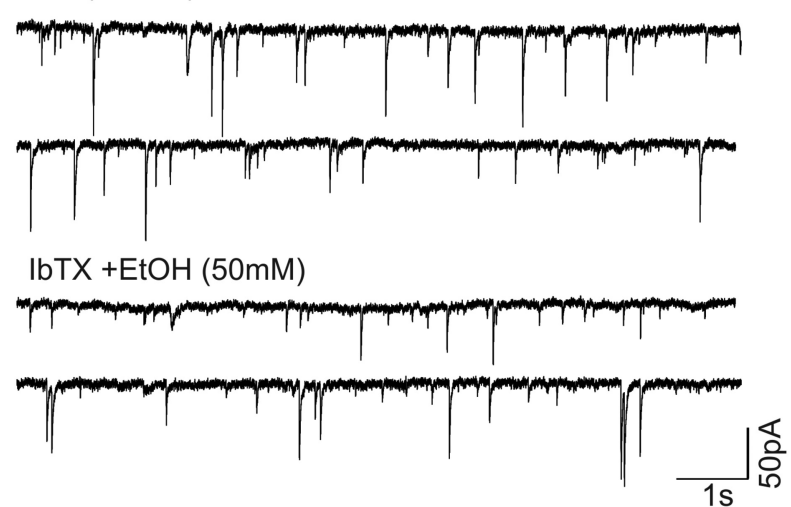

B

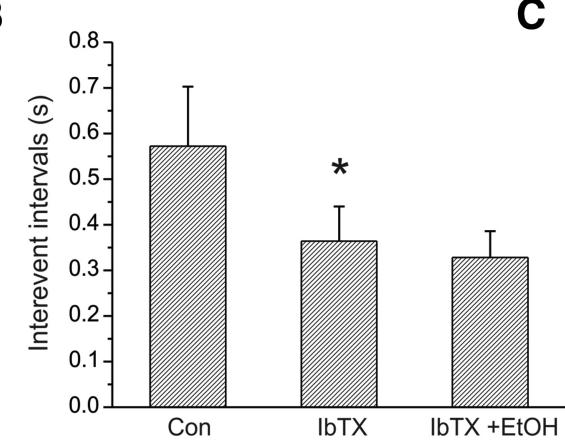

C

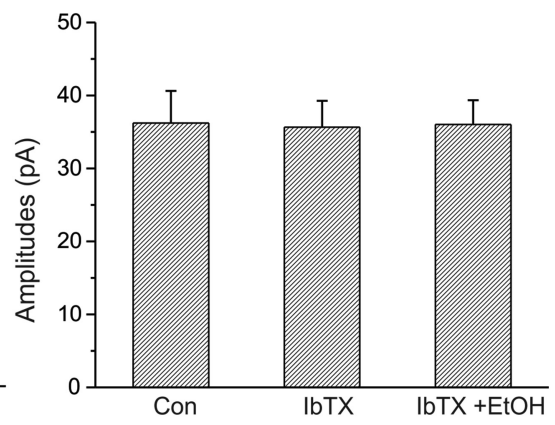

Figure 9. Ethanol fails to increase the frequency of mIPSCs of CeA neurons in the presence of the selective BK channel blocker iberiotoxin. $\boldsymbol{A}$, Traces show mIPSCs recorded from a CeA neuron during control, bath application of iberiotoxin alone, and coapplication of iberiotoxin and ethanol $(50 \mathrm{~mm}) . \boldsymbol{B}$, Interevent interval of mIPSCs was significantly decreased following bath application of iberiotoxin $\left({ }^{*} p<0.05 ; n=7\right)$, but ethanol does not alter mIPSC interevent intervals in the presence of iberiotoxin. $\boldsymbol{C}$, There are no changes in the mean amplitude of mIPSCs after bath application of either iberiotoxin or iberiotoxin plus ethanol $(p>0.05)$.

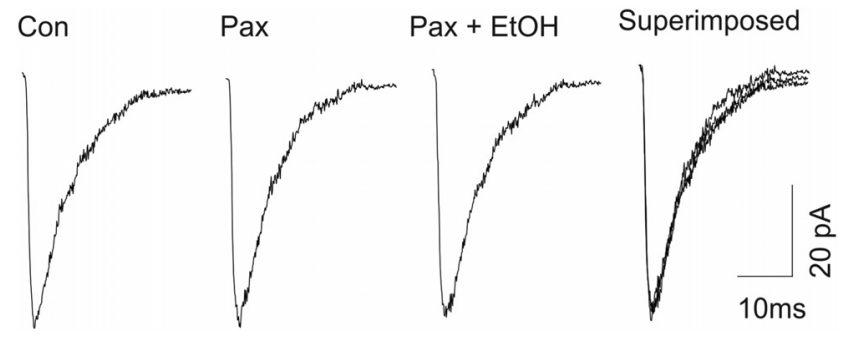

Figure 10. Analysis of the rise times and decay times of mIPSCS of CeA neurons revealed no changes in kinetics in the presence of paxilline $(10 \mathrm{~mm})$ or paxilline plus EtOH $(50 \mathrm{~mm})$ compared with control. Calibration: $5 \mathrm{~ms}, 30 \mathrm{pA}$.

anol (Treistman and Martin, 2009). However, in this preparation, ethanol potentiates BK activity, with no development of acute tolerance (Martin et al., 2008). Furthermore, the ethanol sensitivity of BK channels appears to be determined by the composition of the auxiliary $\beta$ subunits. For example, acute tolerance was observed in mice lacking the $\beta 4$ subunit of the BK channel heteromer, and these findings in cultured cells paralleled acute behavioral effects of ethanol in mice, both WT and $\beta 4$ subunit KOs (Martin et al., 2008). In the neurohypophysial system, somatic $\beta 1$-containing $\mathrm{BK}$ channels appear to be insensitive to ethanol. However, ethanol shows inhibitory effects on BK channels in the peripheral vascular system, and this appears to be largely mediated by $\beta 1$ containing BK channels (Bukiya et al., 2009). Our data showing similar effects of paxilline and iberiotoxin suggest that the inhibitory effects we observe in CeA are mediated by non- $\beta 4$ subunit-containing BK channels, and thus likely involve $\beta 1$ containing channels (although brain tissue contains mRNA for $\beta 2$ and $\beta 3$ subunits, these have not been found to be associated with the $\alpha$ pore-forming units; Treistman and Martin, 2009). Thus, the BK channels active at CeA terminals appear to resemble those of the peripheral vascular system (Bukiya et al., 2009). However, as the maximal effects of iberiotoxin appeared to be somewhat less than paxilline (though not statistically significant), we cannot rule out the possibility of $\beta 4$-containing channels present on the CeA terminals. Additionally, although the $\beta$ auxiliary subunits likely play an important role in the sensitivity of BK channels to ethanol, various other factors, including calcium concentration (Liu et al., 2008) and lipid bilayer composition (Crowley et al., 2005; Yuan et al., 2008), determine the extent and direction of ethanol action on BK channels.

Previous studies in CeA also indicate a postsynaptic mechanism in ethanol enhancement of inhibitory neurotransmission (Roberto et al., 2003). Our current study was focused primarily on ethanol actions at presynaptic sites, as previous work from our group and others indicate reproducible presynaptic effects. In addition, previous studies have suggested that terminal BK channels are sensitive to ethanol, while somatodendritic BK channels are not (Brodie et al., 2007; Wynne et al., 2009). We did note that some individual neurons showed enhanced MIPSC amplitude to ethanol application. However, this effect was quite variable such that the mean mIPSC amplitude (Fig. 7) did not show a statistically significant postsynaptic effect of ethanol on GABAergic responses. These results, however, are quite similar to those reported previously (Roberto et al., 2003). An additional variable is that our studies used cesium in the intracellular electrode filling solution, thus blocking virtually all potassium channels in the soma and proximal dendrites. Therefore, our current studies would not have detected the effects of ethanol on somatic BK channels. We are planning further studies to clarify the possibility of such an effect.

BK channels have an obligate interaction with voltagedependent calcium channels (Berkefeld et al., 2006). In addition, 
A

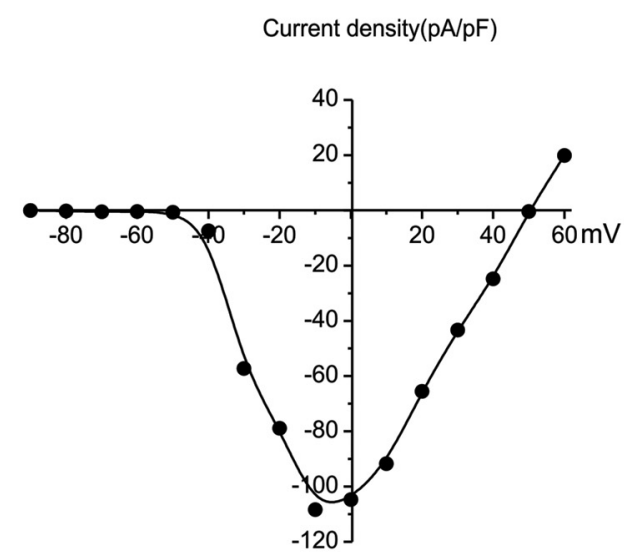

B

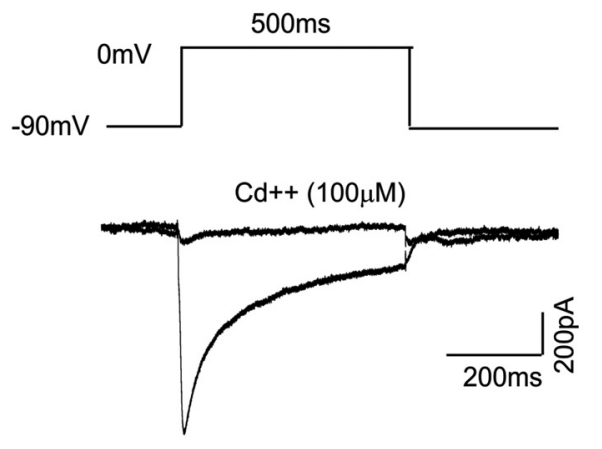

D
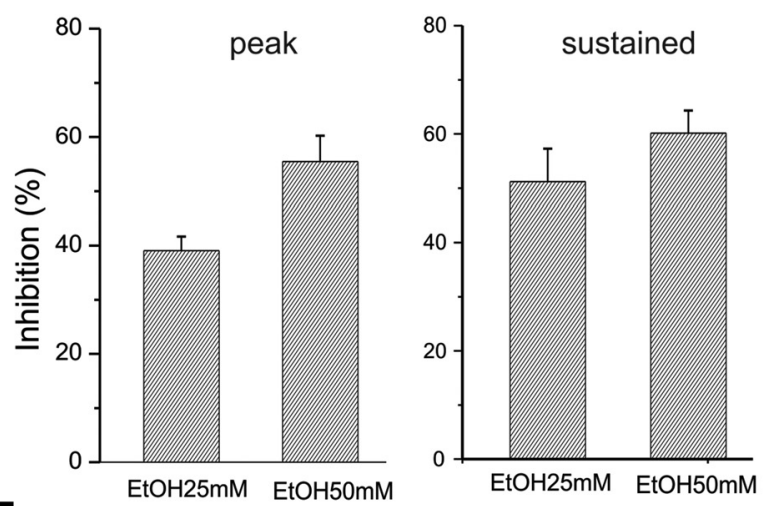

E

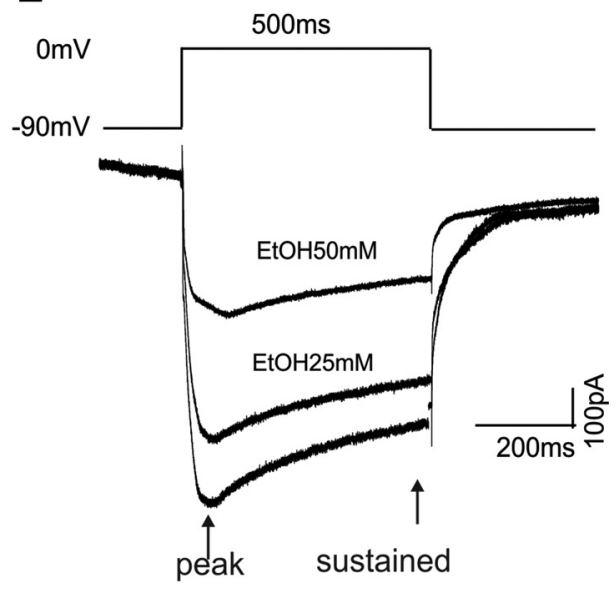

$\mathbf{F}$

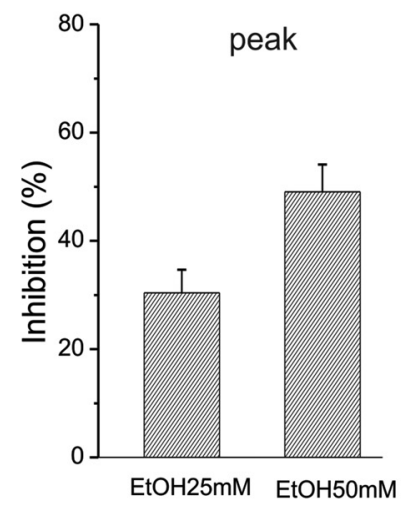

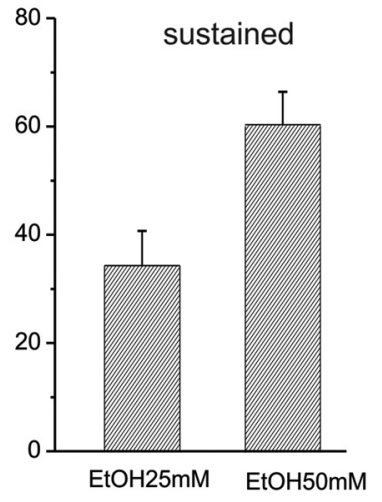

Figure 11. EtOH inhibits whole-cell calcium currents recorded from CeA neurons. $A$, Voltage dependence of the total calcium current density in CeA neurons in which calcium ions are the charge carriers. Currents were elicited by $500 \mathrm{~ms}$ depolarizing test steps between -90 and $60 \mathrm{mV}$ in $10 \mathrm{mV}$ increments. $\boldsymbol{B}$, The total calcium current can be completely abolished following bath application of the nonselective calcium channel blocker cadmium $(100 \mu \mathrm{M})$. The voltage step for eliciting whole-cell calcium current is shown. $C$, Representative traces of calcium currents elicited by depolarizing neurons to $0 \mathrm{mV}$ from $-90 \mathrm{mV}$ in response to bath application of 25 and $50 \mathrm{~mm}$ ethanol. The whole-cell total calcium currents were recorded using an internal solution containing calcium ions as charge carriers. $\boldsymbol{D}$, Significant inhibitory effects of $25 \mathrm{~mm}(n=5)$ and $50 \mathrm{~mm}(n=11)$ ethanol on the total calcium currents are shown for both the peaks (left) and sustained components of total calcium currents (right). $\boldsymbol{E}$, Representative whole-cell traces of barium currents elicited by depolarizing neurons to $0 \mathrm{mV}$ from $-90 \mathrm{mV}$ in response to bath application of 25 and $50 \mathrm{~mm}$ ethanol. The whole-cell total currents were recorded using an internal solution containing barium ions as charge carriers. $\boldsymbol{F}$, Significant inhibitory effects of $25 \mathrm{~mm}(n=10)$ and $50 \mathrm{~mm}(n=8)$ ethanol on the total calcium current are shown for the peaks measured at $20 \mathrm{~ms}$ (left graph) and $450 \mathrm{~ms}$ (right graph) following the start of the depolarizing step.

calcium is required for ethanol actions on BK, while ethanol also facilitates the binding of calcium to the calcium-sensing bowl on the BK channel complex (Liu et al., 2008). Our data on ethanol effects on whole-cell L-type calcium currents are not consistent with the general notion that ethanol enhances neuropeptide release by increasing calcium influx (as opposed to BK channel inhibition). Previous work has also shown the inhibition of $\mathrm{N}$ and P/Q type calcium channels by ethanol (Solem et al., 1997), which 
are known to regulate presynaptic transmitter release. However, these data raise the intriguing possibility that at least some of the inhibitory effect of ethanol on BK channel activity may be due to the decreased availability of local intracellular calcium. Alternately, the blockade of BK channels by ethanol at the presynaptic terminal may facilitate calcium entry, thus enhancing transmitter release.

The results of our current study indicate that BK channels in the CeA may serve as a target for acute ethanol effects, possibly mediating ethanol effects on GABAergic neurotransmission (Roberto et al., 2003). Previous work from our laboratory and others indicates that this action may be critical to the reinforcing and anxiolytic effects of ethanol consumption (Koob et al., 1998). Thus, future studies should address the possibility that the BK channel, and possibly BK channel auxiliary $\beta$ subunits, may serve as a target for pharmacotherapies modulating voluntary ethanol consumption.

\section{References}

Berkefeld H, Sailer CA, Bildl W, Rohde V, Thumfart JO, Eble S, Klugbauer N, Reisinger E, Bischofberger J, Oliver D, Knaus HG, Schulte U, Fakler B (2006) BKCa-Cav channel complexes mediate rapid and localized $\mathrm{Ca} 2+$-activated $\mathrm{K}+$ signaling. Science 314:615-620. CrossRef Medline

Brodie MS, Scholz A, Weiger TM, Dopico AM (2007) Ethanol interactions with calcium-dependent potassium channels. Alcohol Clin Exp Res 31: 1625-1632. CrossRef Medline

Bukiya AN, Liu J, Dopico AM (2009) The BK channel accessory betal subunit determines alcohol-induced cerebrovascular constriction. FEBS Lett 583:2779-2784. CrossRef Medline

Bukiya AN, Kuntamallappanavar G, Edwards J, Singh AK, Shivakumar B, Dopico AM (2014) An alcohol-sensing site in the calcium- and voltagegated, large conductance potassium (BK) channel. Proc Natl Acad Sci U S A 111:9313-9318. CrossRef Medline

Cowmeadow RB, Krishnan HR, Ghezzi A, Al'Hasan YM, Wang YZ, Atkinson NS (2006) Ethanol tolerance caused by slowpoke induction in Drosophila. Alcohol Clin Exp Res 30:745-753. CrossRef Medline

Crowley JJ, Treistman SN, Dopico AM (2005) Distinct structural features of phospholipids differentially determine ethanol sensitivity and basal function of BK channels. Mol Pharmacol 68:4-10. CrossRef Medline

Davis SJ, Scott LL, Hu K, Pierce-Shimomura JT (2014) Conserved single residue in the BK potassium channel required for activation by alcohol and intoxication in C. elegans. J Neurosci 34:9562-9573. CrossRef Medline

Faber ES, Sah P (2002) Physiological role of calcium-activated potassium currents in the rat lateral amygdala. J Neurosci 22:1618-1628. Medline

Faber ES, Sah P (2003) Ca2+-activated K+ (BK) channel inactivation contributes to spike broadening during repetitive firing in the rat lateral amygdala. J Physiol 552:483-497. CrossRef Medline

Foster KL, McKay PF, Seyoum R, Milbourne D, Yin W, Sarma PV, Cook JM, June HL (2004) GABA(A) and opioid receptors of the central nucleus of the amygdala selectively regulate ethanol-maintained behaviors. Neuropsychopharmacology 29:269-284. CrossRef Medline

Gorini G, Ponomareva O, Shores KS, Person MD, Harris RA, Mayfield RD (2010) Dynamin-1 co-associates with native mouse brain BKCa channels: proteomics analysis of synaptic protein complexes. FEBS Lett 584: 845-851. CrossRef Medline

Hyytiä P, Koob GF (1995) GABAA receptor antagonism in the extended amygdala decreases ethanol self-administration in rats. Eur J Pharmacol 283:151-159. CrossRef Medline

Jackson MB, Konnerth A, Augustine GJ (1991) Action potential broadening and frequency-dependent facilitation of calcium signals in pituitary nerve terminals. Proc Natl Acad Sci U S A 88:380-384. CrossRef Medline

Kang-Park MH, Kieffer BL, Roberts AJ, Siggins GR, Moore SD (2007) Presynaptic delta opioid receptors regulate ethanol actions in central amygdala. J Pharmacol Exp Ther 320:917-925. CrossRef Medline
Kang-Park MH, Kieffer BL, Roberts AJ, Roberto M, Madamba SG, Siggins GR, Moore SD (2009) Mu-opioid receptors selectively regulate basal inhibitory transmission in the central amygdala: lack of ethanol interactions. J Pharmacol Exp Ther 328:284-293. CrossRef Medline

Kang-Park M, Kieffer BL, Roberts AJ, Siggins GR, Moore SD (2013) kappaOpioid receptors in the central amygdala regulate ethanol actions at presynaptic GABAergic sites. J Pharmacol Exp Ther 346:130-137. CrossRef Medline

Knott TK, Dayanithi G, Coccia V, Custer EE, Lemos JR, Treistman SN (2000) Tolerance to acute ethanol inhibition of peptide hormone release in the isolated neurohypophysis. Alcohol Clin Exp Res 24:1077-1083. CrossRef Medline

Koob GF, Roberts AJ, Schulteis G, Parsons LH, Heyser CJ, Hyytiä P, MerloPich E, Weiss F (1998) Neurocircuitry targets in ethanol reward and dependence. Alcohol Clin Exp Res 22:3-9. CrossRef Medline

Läck AK, Floyd DW, McCool BA (2005) Chronic ethanol ingestion modulates proanxiety factors expressed in rat central amygdala. Alcohol 36:83-90. CrossRef Medline

Lee SC, Choi S, Lee T, Kim HL, Chin H, Shin HS (2002) Molecular basis of R-type calcium channels in central amygdala neurons of the mouse. Proc Natl Acad Sci U S A 99:3276-3281. CrossRef Medline

Liu J, Vaithianathan T, Manivannan K, Parrill A, Dopico AM (2008) Ethanol modulates BKCa channels by acting as an adjuvant of calcium. Mol Pharmacol 74:628-640. CrossRef Medline

Liu Q, Chen B, Ge Q, Wang ZW (2007) Presynaptic $\mathrm{Ca}^{2+} /$ calmodulindependent protein kinase II modulates neurotransmitter release by activating BK channels at Caenorhabditis elegans neuromuscular junction. J Neurosci 27:10404-10413. CrossRef Medline

Martin GE, Hendrickson LM, Penta KL, Friesen RM, Pietrzykowski AZ, Tapper AR, Treistman SN (2008) Identification of a BK channel auxiliary protein controlling molecular and behavioral tolerance to alcohol. Proc Natl Acad Sci U S A 105:17543-17548. CrossRef Medline

McBride WJ (2002) Central nucleus of the amygdala and the effects of alcohol and alcohol-drinking behavior in rodents. Pharmacol Biochem Behav 71:509-515. CrossRef Medline

Menzaghi F, Rassnick S, Heinrichs S, Baldwin H, Pich EM, Weiss F, Koob GF (1994) The role of corticotropin-releasing factor in the anxiogenic effects of ethanol withdrawal. Ann N Y Acad Sci 739:176-184. CrossRef Medline

Nie Z, Schweitzer P, Roberts AJ, Madamba SG, Moore SD, Siggins GR (2004) Ethanol augments GABAergic transmission in the central amygdala via CRF1 receptors. Science 303:1512-1514. CrossRef Medline

Poncer JC, McKinney RA, Gähwiler BH, Thompson SM (1997) Either N- or P-type calcium channels mediate GABA release at distinct hippocampal inhibitory synapses. Neuron 18:463-472. CrossRef Medline

Roberto M, Madamba SG, Moore SD, Tallent MK, Siggins GR (2003) Ethanol increases GABAergic transmission at both pre- and postsynaptic sites in rat central amygdala neurons. Proc Natl Acad Sci U S A 100:20532058. CrossRef Medline

Roberto M, Madamba SG, Stouffer DG, Parsons LH, Siggins GR (2004) Increased GABA release in the central amygdala of ethanol-dependent rats. J Neurosci 24:10159-10166. CrossRef Medline

Roberto M, Treistman SN, Pietrzykowski AZ, Weiner J, Galindo R, Mameli M, Valenzuela F, Zhu PJ, Lovinger D, Zhang TA, Hendricson AH, Morrisett R, Siggins GR (2006) Actions of acute and chronic ethanol on presynaptic terminals. Alcohol Clin Exp Res 30:222-232. CrossRef Medline

Sausbier U, Sausbier M, Sailer CA, Arntz C, Knaus HG, Neuhuber W, Ruth P (2006) $\mathrm{Ca} 2+$-activated $\mathrm{K}+$ channels of the BK-type in the mouse brain. Histochem Cell Biol 125:725-741. CrossRef Medline

Solem M, McMahon T, Messing RO (1997) Protein kinase A regulates regulates inhibition of $\mathrm{N}$ - and P/Q-type calcium channels by ethanol in PC12 cells. J Pharmacol Exp Ther 282:1487-1495. Medline

Tabak J, Tomaiuolo M, Gonzalez-Iglesias AE, Milescu LS, Bertram R (2011) Fast-activating voltage- and calcium-dependent potassium (BK) conductance promotes bursting in pituitary cells: a dynamic clamp study. J Neurosci 31:16855-16863. CrossRef Medline

Treistman SN, Martin GE (2009) BK Channels: mediators and models for alcohol tolerance. Trends Neurosci 32:629-637. CrossRef Medline

Tsien RW, Lipscombe D, Madison DV, Bley KR, Fox AP (1988) Multiple 
types of neuronal calcium channels and their selective modulation. Trends Neurosci 11:431-438. CrossRef Medline

Walter HJ, Messing RO (1999) Regulation of neuronal voltage-gated calcium channels by ethanol. Neurochem Int 35:95-101. CrossRef Medline

Wynne PM, Puig SI, Martin GE, Treistman SN (2009) Compartmentalized beta subunit distribution determines characteristics and ethanol sensitivity of somatic, dendritic, and terminal large-conductance calcium-activated potassium channels in the rat central nervous system. J Pharmacol Exp Ther 329: 978-986. CrossRef Medline

Yu B, Shinnick-Gallagher P (1997) Dihydropyridine- and neurotoxinsensitive and -insensitive calcium currents in acutely dissociated neurons of the rat central amygdala. J Neurophysiol 77:690-701. Medline
Yu B, Shinnick-Gallagher P (1998) Corticotropin-releasing factor increases dihydropyridine- and neurotoxin-resistant calcium currents in neurons of the central amygdala. J Pharmacol Exp Ther 284:170179. Medline

Yuan C, O'Connell RJ, Wilson A, Pietrzykowski AZ, Treistman SN (2008) Acute alcohol tolerance is intrinsic to the BKCa protein, but is modulated by the lipid environment. J Biol Chem 283:5090-5098. CrossRef Medline

Zucca S, Valenzuela CF (2010) Low concentrations of alcohol inhibit BDNF-dependent GABAergic plasticity via L-type $\mathrm{Ca}^{2+}$ channel inhibition in developing CA3 hippocampal pyramidal neurons. J Neurosci 30: 6776-6781. CrossRef Medline 